\title{
Optimization of machining parameters and wire vibration in wire electrical discharge machining process
}

Sameh Habibid

\begin{abstract}
Background: Wire Electrical discharge machining (WEDM) has higher capability for cutting complex shapes with high precision for very hard materials without using high cost of cutting tools. During the WEDM process, the wire behaves like a metal string, straightened by two axial pulling forces and deformed laterally by a sum of forces from the discharge process. Major forces acting on the wire can be classified into three categories. The first is a tensile force, pulling the wire from both sides in axial direction and keeping it straight. The second is the dielectric flushing force that comes from circulation of the dielectric fluid in the machining area. The third category consists of forces of different kinds resulting from sparking and discharging. Large amplitude of wire vibration leads to large kerf widths, low shape accuracies, rough machined surfaces, low cutting speeds and high risk of wire breakage. Such tendencies for poor machining performance due to wire instability behavior appear with thinner wires.

Methods: The present work investigates a mathematical modeling solution for correlating the interactive and higher order influences of various parameters affecting wire vibration during the WEDM process through response surface methodology (RSM). The adequacy of the above proposed model has been tested using analysis of variance (ANOVA).
\end{abstract}

Results: Optimal combination of machining parameters such as wire tension, wire running speed, flow rate and servo voltage parameters has been obtained to minimize wire vibration.

Conclusions: The analysis of the experimental observations highlights that the wire tension, wire running speed, flow rate and servo voltage in WEDM greatly affect average wire vibration and kerf width.

Keywords: Wire electrical discharge machining (WEDM), Mathematical modeling, Wire vibration, Kerf width and response surface methodology (RSM)

\section{Background}

Wire electrical discharge machining is a thermo-electrical process in which material is eroded from the workpiece through a series of discrete sparks occurring between the workpiece and the wire electrode (tool). The tool is separated by a thin film of dielectric fluid which is continuously fed to the area being machined in order to flush away the eroded particles. The movement of the wire is numerically controlled to achieve the desired three-dimensional shape and accuracy of the workpiece. The most important performance factors effecting WEDM are discharge current, pulse duration, pulse frequency, wire speed, wire tension,

Correspondence: samehhabib67@outlook.com; sameh.abadir@feng.bu.edu.eg Mechanical Engineering Department, Faculty of Engineering at Shoubra, Benha University, Cairo, Egypt 
al. 1996). They analyzed the force components that influence the wire during machining. Several researchers focused on the measurement of static deflection of the wire (wire lag). However, mathematical modeling of vibration behavior of the wire needs to be studied because it plays an important role in deciding precision and accuracy of wire EDM products.

Geometrical inaccuracy due to wire lag phenomenon in wire-cut electrical discharge machining has been analyzed and optimized by (Puri \& Bhattacharyya 2003). Also, the trend of variation of the geometrical inaccuracy caused due to wire lag with various machine control parameters has been studied. Shichun et al. (2009) analyzed kerf width of micro wire EDM. They developed mathematical model of wire lateral vibration in machining process. Kumar et al. (2013) studied describes the effect of six input parameters such as pulse-on time, pulse-off time, peak current, spark gap voltage, wire feed and wire tension on wire breakage frequency and the surface integrity of wear out wire during machining of pure titanium. Wentai et al. (2015) investigated wire tension change in high speed wire EDM. They developed simulation model for the process and redesigned wire winding mechanism to improve cutting stability as well as the consistency of workpiece dimension in multicutting process. In addition, the higher tension decreases the wire vibration amplitude and hence decreases the cut width so that the speed is higher for the same discharge energy. However, if the applied tension exceeds the tensile strength of the wire, it leads to wire breakage. Kumar \& Singh (2012) investigated the variation of cutting performance with pulse on time, pulse off time, open voltage, feed

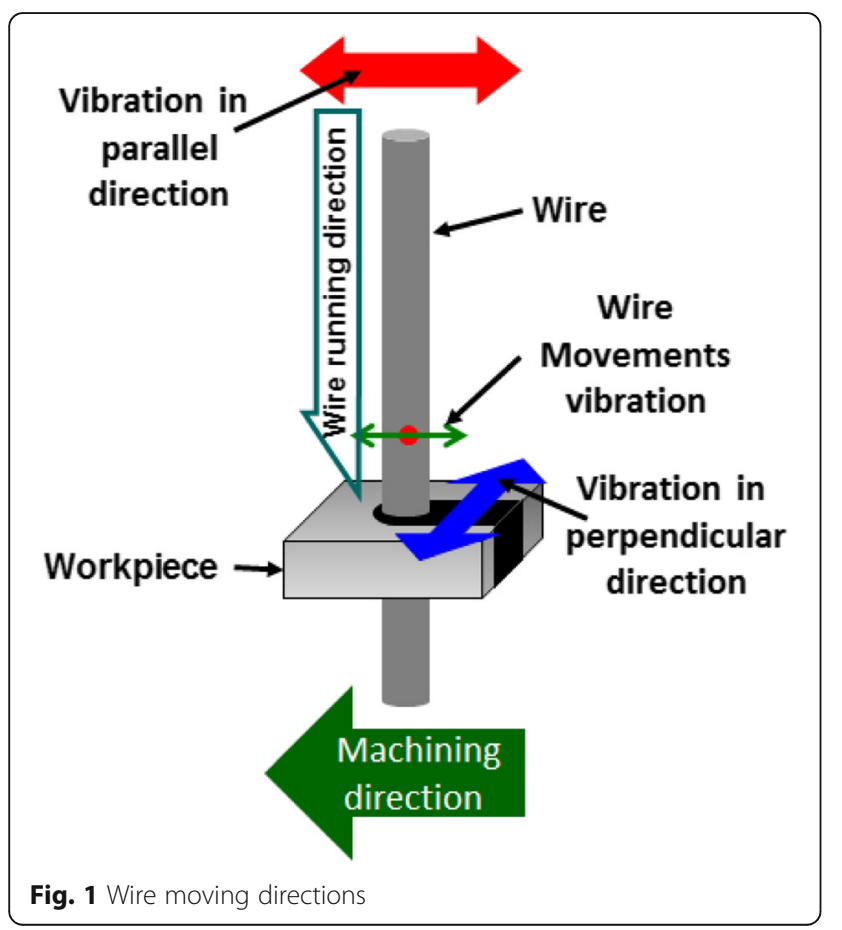

Table 1 Properties of dielectric fluid

\begin{tabular}{ll}
\hline Dielectric fluid property & Value \\
\hline Flushing point & $125^{\circ} \mathrm{C}$ \\
Melting point & $-51{ }^{\circ} \mathrm{C}$ \\
Boiling point & $300{ }^{\circ} \mathrm{C}$ \\
Appearance & colorless \\
Specific Gravity & 0.8236 \\
Odor & odorless \\
\hline
\end{tabular}

rate override, wire feed, servo voltage, wire tension and flushing pressure. They used Taguchi approach of L18 orthogonal array under different conditions to obtain optimal combination of parameters. Nain et al (2015) reviews the effect of process parameters on the performance characteristics such as surface integrity characteristics and roughness, material removal rate, kerf width and wire wear rate of wire EDM process.

Wire movements vibration during wire EDM process were directly observed by (Habib \& Okada 2016a; Habib \& Okada 2016b) using a high-speed video camera. Highspeed observation model was built, and the wire movements during machining were observed and recorded. By analyzing the recorded images, the effects of machining conditions such as wire tension, wire running speed, flow rate of jet flushing and servo voltage on the wire vibration amplitude and machined kerf width were developed. In this work, mathematical models for correlating these machining conditions with wire vibration amplitude and machined kerf width were developed. Response surface methodology was used to optimize machining conditions utilizing the relevant experimental data as obtained through experimentation. The adequacy of the developed mathematical models has also been tested by the analysis of variance test.

Table 2 Experimental working conditions

\begin{tabular}{ll}
\hline Working conditions & Value \\
\hline Machining length & $5.0 \mathrm{~mm}$ \\
Workpiece material & SKD11 (JIS) \\
Workpiece thickness & $1.0 \mathrm{~mm}$ \\
Pulse duration $\mathrm{t}_{\mathrm{e}}$ & $1.0 \mathrm{\mu s}$ \\
Discharge current $\mathrm{i}_{\mathrm{e}}$ & $20 \mathrm{~A}$ \\
Wire diameter & $0.5 \mathrm{~mm}$ \\
Wire material & Tungsten \\
Wire tension $\mathrm{W}_{\mathrm{t}}$ & $0.5-4.0 \mathrm{~N}$ \\
Wire running speed $\mathrm{W}_{\mathrm{s}}$ & $1.0-15.0 \mathrm{~m} / \mathrm{min}$ \\
Servo voltage $\mathrm{S}_{\mathrm{v}}$ & $50-90 \mathrm{~V}$ \\
Flow rate $\mathrm{F}_{\mathrm{r}}$ & $0-8.0 \mathrm{~L} / \mathrm{min}$ \\
Dielectric fluid & Kerosene \\
\hline
\end{tabular}




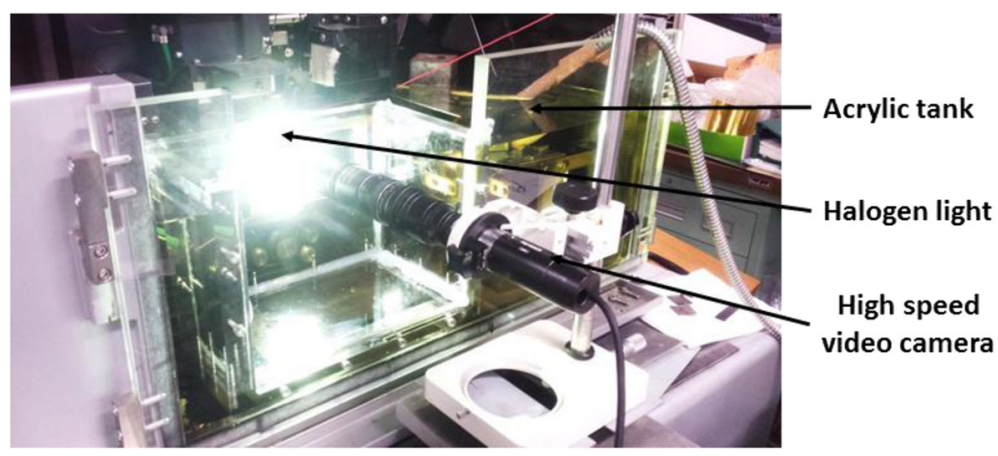

Fig. 2 High-speed observation system of WEDM

\section{Methods}

In order to study the influence of machining conditions such as wire tension, wire running speed, flow rate of jet flushing and servo voltage on the wire vibration amplitude and machined kerf width, tests were carried out on 5 -axis computer numerical control type wire electric discharge machine called "Sodick AP200L". The workpiece material was SKD11 in JIS specifications of $1.0 \mathrm{~mm}$ thickness. SKD11 (alloy tool steel) is high-Carbon highChromium alloy steel possessing high hardness, strength and wear resistance. Its surface is grinded precisely. It is often used for the stamping dies, plastic molds. An acrylic small tank filled with dielectric oil fluid (Kerosene type) is used to facilitate the developed observation system. Table 1 lists the properties of dielectric fluid. The experimental working conditions were listed in Table 2 .

High-speed observation system of fine wire EDM was used in this work as shown in Fig. 2. The wire movements during the process were observed by a high-speed video camera. The digital high-speed video camera system (KEYENCE VW-6000) was used for the recording with the aid of a Halogen light source. The recording conditions are listed in Table 3. The wire vibration during the process was analyzed with the motion analysis program (DITECT DIPP Motion Pro). This software was used for the analysis of recorded images obtained using a high-speed video camera (DIPP Motion Pro User s Manual). In order to accurately analyze a vibration problem, it is necessary to describe the vibration in a consistent and reliable manner. Vibration analysts rely primarily on numerical descriptions, rather than on verbal descriptions, to analyze vibration accurately. Amplitude describes the severity of vibration, and

Table 3 Digital video camera recording conditions

\begin{tabular}{ll}
\hline Recording conditions & Value \\
\hline Recording speed & $8,000 \mathrm{fps}$ \\
Shutter speed & $1 / 40,000 \mathrm{~s}$ \\
Recording time & $2.0 \mathrm{~s}$ \\
View size & $0.4 \times 0.2 \mathrm{~mm}$ \\
\hline
\end{tabular}

frequency describes the oscillation rate of vibration (how frequently an object vibrates) (Habib \& Okada 2016a). Average wire amplitude, which is simply the arithmetic average of the signal level over a certain length of time. Kerf width was measured by using NIKON high optical microscope under magnification of 100 times. Kerf width measurements were made three times at three different positions along the kerf width and the average value was calculated.

\section{Response surface modelling and experimental design}

Response surface methodology (RSM) is a collection of mathematical and statistical techniques for empirical model building. By careful design of experiments, the objective is to optimize a response (output variable) which is influenced by several independent variables (input variables). An experiment is a series of tests, called runs, in which changes are made in the input variables in order to identify the reasons for changes in the output response (Mahfouz 1999). In this work response surface methodology was chosen meanwhile many other techniques are available because it explores the relationships between several explanatory variables and one or more response variables. The main idea of RSM is to use a sequence of designed experiments to obtain an optimal response.

Most of the criteria for optimal design of experiments are associated with the mathematical model of the process. Generally, these mathematical models are polynomials with an unknown structure, so the corresponding experiments are designed only for every particular problem. The choice of the design of experiments can have a large influence on the accuracy of the approximation and the cost of constructing the response surface. A second-order model can be constructed efficiently with central composite designs (CCD) (Montgomery 1997). $\mathrm{CCD}$ are first-order $\left(2^{\mathrm{K}}\right)$ designs augmented by additional centre and axial points to allow estimation of the tuning parameters of a second-order model. the design involves 
$2^{\mathrm{K}}$ factorial points, $2 \mathrm{~K}$ axial points and 1 central point repeated 7 times (Habib 2009).

In this study average wire amplitude (Aa) and kerf width $(\mathrm{Wk})$ are selected as the response (output variables). However, the independent (input variables) are wire tension (Wt), wire running speed (Ws), flow rate (Fr) and servo voltage (Sv). The coded levels for input variables are listed in Table 4. The minimum possible number of experiments (N) can be determined from the following equations by using "Minitab 16" software:

$$
\mathrm{N}=2^{\mathrm{K}}+2 \mathrm{~K}+7
$$

When $\mathrm{K}$ equals 4 (input variables), thus the minimum number of experiments involves a total of 31 experimental observations with different combinations of input variables. In order to study the effects of the input variables on the above responses, second order polynomial response surface mathematical models can be developed. In the general case, the response surface is described by an equation of the form:

$$
Y_{u}=\beta_{\circ}+\sum_{i=1}^{K} \beta_{i} x_{i}+\sum_{i=1}^{K} \beta_{i i} x_{i}^{2}+\sum_{i\rangle i}^{K} \beta_{i j} x_{i} x_{j} \ldots
$$

Where, $Y_{u}$ is the corresponding response, e.g. the Aa and $\mathrm{Wk}$ produced by the various input variables and the $\mathrm{x}_{\mathrm{i}}(1,2, \ldots \mathrm{k})$ are coded levels of $\mathrm{k}$ quantitative process variables, the terms $\beta_{\circ}, \beta_{\mathrm{i}}, \beta_{\mathrm{ii}}$ and $\beta_{\mathrm{ij}}$ are the second order regression coefficients. The second term under the summation sign of this polynomial equation is attributable to linear effect, whereas the third term corresponds to the higher-order effects; the fourth term of the equation includes the interactive effects of the process parameters. In this work, Eq. (2) can be rewritten according to the four variables used as:

$$
\begin{aligned}
Y_{u} & =\beta_{0}+\beta_{1} x_{1}+\beta_{2} x_{2}+\beta_{3} x_{3}+\beta_{4} x_{4}+\beta_{11} x_{1}^{2}+\beta_{22} x_{2}^{2}+\beta_{33} x_{3}^{2} \\
& +\beta_{44} x_{4}^{2}+\beta_{12} x_{1} x_{2}+\beta_{13} x_{1} x_{3}+\beta_{14} x_{1} x_{4}+\beta_{23} x_{2} x_{3}+\beta_{24} x_{2} x_{4} \\
& +\beta_{34} x_{3} x_{4} \ldots \ldots . .
\end{aligned}
$$

Where: $X_{1}, X_{2}, X_{3}$ and $X_{4}$ are wire tension, wire running speed, flow rate and servo voltage respectively.

\begin{tabular}{|c|c|c|c|c|c|c|}
\hline $\begin{array}{l}\text { Experiment } \\
\text { No. }\end{array}$ & Wt & Ws & $\mathrm{Fr}$ & Sv & Response $\mathrm{Aa}(\mu \mathrm{m})$ & Response Wk ( $\mu \mathrm{m})$ \\
\hline 1 & -2 & 0 & 0 & 0 & 3.66540 & 71.5790 \\
\hline 2 & 0 & 0 & 0 & 0 & 2.37396 & 68.0022 \\
\hline 3 & -1 & 1 & 1 & -1 & 2.54925 & 68.3599 \\
\hline 4 & 0 & 0 & 0 & 0 & 2.37396 & 68.0022 \\
\hline 5 & -1 & -1 & 1 & -1 & 2.93253 & 70.4804 \\
\hline 6 & -1 & -1 & -1 & -1 & 2.70124 & 69.2480 \\
\hline 7 & 2 & 0 & 0 & 0 & 2.17943 & 65.7750 \\
\hline 8 & 0 & 0 & 0 & 0 & 2.37396 & 68.0022 \\
\hline 9 & -1 & 1 & -1 & -1 & 2.70124 & 69.2480 \\
\hline 10 & -1 & 1 & -1 & 1 & 2.66031 & 69.1647 \\
\hline 11 & 0 & 0 & 0 & 0 & 2.37396 & 68.0022 \\
\hline 12 & 1 & 1 & 1 & 1 & 2.01800 & 66.6289 \\
\hline 13 & 1 & 1 & 1 & -1 & 1.84065 & 65.8024 \\
\hline 14 & 0 & 2 & 0 & 0 & 2.51052 & 68.3176 \\
\hline 15 & 0 & 0 & -2 & 0 & 2.62025 & 68.8408 \\
\hline 16 & 0 & 0 & 0 & 0 & 2.37396 & 68.0022 \\
\hline 17 & 0 & 0 & 0 & 0 & 2.37396 & 68.0022 \\
\hline 18 & -1 & -1 & -1 & 1 & 2.66031 & 69.1647 \\
\hline 19 & 0 & 0 & 0 & -2 & 2.43437 & 68.1575 \\
\hline 20 & -1 & 1 & 1 & 1 & 2.83786 & 69.6149 \\
\hline 21 & 0 & 0 & 0 & 2 & 2.60788 & 69.0435 \\
\hline 22 & -1 & -1 & 1 & 1 & 2.95642 & 70.7109 \\
\hline 23 & 1 & -1 & -1 & -1 & 2.24741 & 67.2592 \\
\hline 24 & 1 & 1 & -1 & -1 & 2.04350 & 66.4264 \\
\hline 25 & 1 & -1 & -1 & 1 & 2.09522 & 66.7474 \\
\hline 26 & 0 & 0 & 0 & 0 & 2.37396 & 68.0022 \\
\hline 27 & 0 & -2 & 0 & 0 & 2.55843 & 69.1749 \\
\hline 28 & 0 & 0 & 2 & 0 & 2.64001 & 69.5402 \\
\hline 29 & 1 & 1 & -1 & 1 & 2.15603 & 66.9390 \\
\hline 30 & 1 & -1 & 1 & -1 & 2.69919 & 69.1595 \\
\hline 31 & 1 & -1 & 1 & 1 & 2.61182 & 68.9616 \\
\hline
\end{tabular}

Table 4 Coding levels of input variables

\begin{tabular}{lllll}
\hline Level & Wt & Ws & $\mathrm{Fr}$ & Sv \\
\hline-2 & 0.5 & 1 & 0 & 50 \\
-1 & 1.5 & 3 & 2 & 60 \\
0 & 2 & 7 & 4 & 70 \\
1 & 3 & 11 & 6 & 80 \\
2 & 4 & 15 & 8 & 90 \\
\hline
\end{tabular}

\begin{tabular}{|c|c|c|c|c|c|c|}
\hline Source & $\begin{array}{l}\text { Sum of } \\
\text { squares }\end{array}$ & $\begin{array}{l}\text { Degree of } \\
\text { freedom }\end{array}$ & $\begin{array}{l}\text { Mean } \\
\text { Square }\end{array}$ & $F$ value & $P$ value & \\
\hline Model & 2.45 & 14 & .31 & 32.78 & $<.0001$ & Significant \\
\hline $\begin{array}{l}\text { Pure } \\
\text { error }\end{array}$ & .17 & 16 & & & & \\
\hline $\begin{array}{l}\text { Cor } \\
\text { total }\end{array}$ & 2.62 & 30 & & & & \\
\hline \multicolumn{2}{|c|}{$\begin{array}{l}\text { R-Squared } \\
=.9358\end{array}$} & \multicolumn{2}{|c|}{$\begin{array}{l}\text { Adj R -Squared } \\
=.9072\end{array}$} & & & \\
\hline
\end{tabular}

Table 5 Plan for central composite rotatable second-order design: different controlling parameters and results

Table 6 ANOVA analysis for Wire amplitude $\left(A_{a}\right)$ 
Table 7 ANOVA analysis for Kerf width (Wk)

\begin{tabular}{lllllll}
\hline Source & $\begin{array}{l}\text { Sum of } \\
\text { squares }\end{array}$ & $\begin{array}{l}\text { Degree of } \\
\text { freedom }\end{array}$ & $\begin{array}{l}\text { Mean } \\
\text { Square }\end{array}$ & $F$ value & $P$ value & \\
\hline Model & .56 & 14 & .070 & 1202.36 & $<.0001$ & Significant \\
Pure error & .00104 & 16 & & & & \\
Cor total & .56 & 30 & & & & \\
R-Squared $=.9981$ & Adj R -Squared $=.9973$ & & \\
\hline
\end{tabular}

\section{Result and Discussion}

\section{Mathematical formulation}

Based on Eq. (3), the effects of the above mentioned process variables on the magnitude of both average wire amplitude (Aa) and kerf width (Wk) has been evaluated by computing the values of the different constants of Eq. (3) and utilizing the relevant data from Table 5. The mathematical models for correlating $\mathrm{Aa}$ and $\mathrm{Wk}$ in addition with the considered process variables were obtained by Eqs. 4 and 5:

$$
\begin{aligned}
\mathrm{A}_{\mathrm{a}}= & 5.98371-1.01661 \mathrm{~W}_{\mathrm{t}}-0.01284 \mathrm{~W}_{\mathrm{s}}-0.11263 \\
& \mathrm{~F}_{\mathrm{r}}-0.05458 \mathrm{~S}_{\mathrm{v}}+0.21820 \mathrm{~W}_{\mathrm{t}}^{2}+0.00342 \\
& \mathrm{~W}_{\mathrm{s}}^{2}+0.01601 \mathrm{~F}_{\mathrm{r}}^{2}+0.00037 \mathrm{~S}_{\mathrm{v}}{ }^{2}-0.03961 \\
& \mathrm{~W}_{\mathrm{t}} \mathrm{W}_{\mathrm{s}}+0.03675 \mathrm{~W}_{\mathrm{t}} \mathrm{F}_{\mathrm{r}}-0.00371 \mathrm{~W}_{\mathrm{t}} \mathrm{S}_{\mathrm{v}}-0.02046 \\
& \mathrm{~W}_{\mathrm{s}} \mathrm{F}_{\mathrm{r}}+0.00165 \mathrm{~W}_{\mathrm{s}} \mathrm{S}_{\mathrm{v}}+0.00081 \mathrm{~F}_{\mathrm{r}} \mathrm{S}_{\mathrm{v}} \\
\mathrm{Wk}= & 80.7126-2.0166 \mathrm{~W}_{\mathrm{t}}-0.2562 \mathrm{~W}_{\mathrm{s}}-0.4518 \\
& \mathrm{~F}_{\mathrm{r}}-0.2192 \mathrm{~S}_{\mathrm{v}}+0.3631 \mathrm{~W}_{\mathrm{t}}{ }^{2}+0.0168 \\
& \mathrm{~W}_{\mathrm{s}}^{2}+0.0743 \mathrm{~F}_{\mathrm{r}}^{2}+0.0015 \mathrm{~S}_{\mathrm{v}}{ }^{2}-0.1031 \\
& \mathrm{~W}_{\mathrm{t}} \mathrm{W}_{\mathrm{s}}+0.1113 \mathrm{~W}_{\mathrm{t}} \mathrm{F}_{\mathrm{r}}-0.0143 \mathrm{~W}_{\mathrm{t}} \mathrm{S}_{\mathrm{v}}-0.0789 \\
& \mathrm{~W}_{\mathrm{s}} \mathrm{F}_{\mathrm{r}}+0.0064 \mathrm{~W}_{\mathrm{s}} \mathrm{S}_{\mathrm{v}}+0.0039 \mathrm{~F}_{\mathrm{r}} \mathrm{S}_{\mathrm{v}}
\end{aligned}
$$

\section{Checking the accuracy of the model}

The adequacy of the above two proposed models have been tested through the analysis of variance (ANOVA). The usual method for testing the adequacy of a model is carried out by computing the F-ratio of the lack of fit to the pure error and comparing it with the standard value. If the F-ratio calculated is less than the standard values, the postulated model is adequate (Nain et al. 2015; DIPP Motion Pro User s Manual). The calculated F-ratios were found to be higher than the tabulated values with a 95\% confidence level and hence the models were considered to be adequate. Another way of determining the accuracy of the fitted regression model is to find the coefficient of determination $\left(R^{2}\right)$. In all the three cases that the values of determination coefficient $\left(R^{2}\right)$ and adjusted determination coefficient (adj. $\mathrm{R}^{2}$ ) are more than $90 \%$ which confirms good significance of the model. The results of the analysis justifying the closeness of fit of the mathematical models have been enumerated, as shown in Tables 6 and 7. The $p$-values of the models are also found to be less than 0.05 , which verifies that the model is acceptable. It is concluded that the evolved models given by Eqs. (4) and (5) are quite adequate and demonstrate the independent, quadratic and interactive effects of the different machining parameters on the average wire amplitude and kerf width criteria values.

\section{Parametric influence on average wire amplitude}

The influence of wire tension, wire running speed, flow rate and servo voltage on average wire amplitude can be shown in Fig. 3. Average wire amplitude decreases with the increase of wire tension and wire running speed. However, it increases with dielectric flow rate. Servo voltage has a weak influence on average wire amplitude. One of the most effecting parameters of wire vibration amplitude in wire EDM process is wire tension. Figure 4 shows wire shape difference under wire tension 0.5 and 4.0 N. Within considerable range, an increase in wire tension significantly increases the cutting speed and accuracy due to the sharp straightness of the wire.

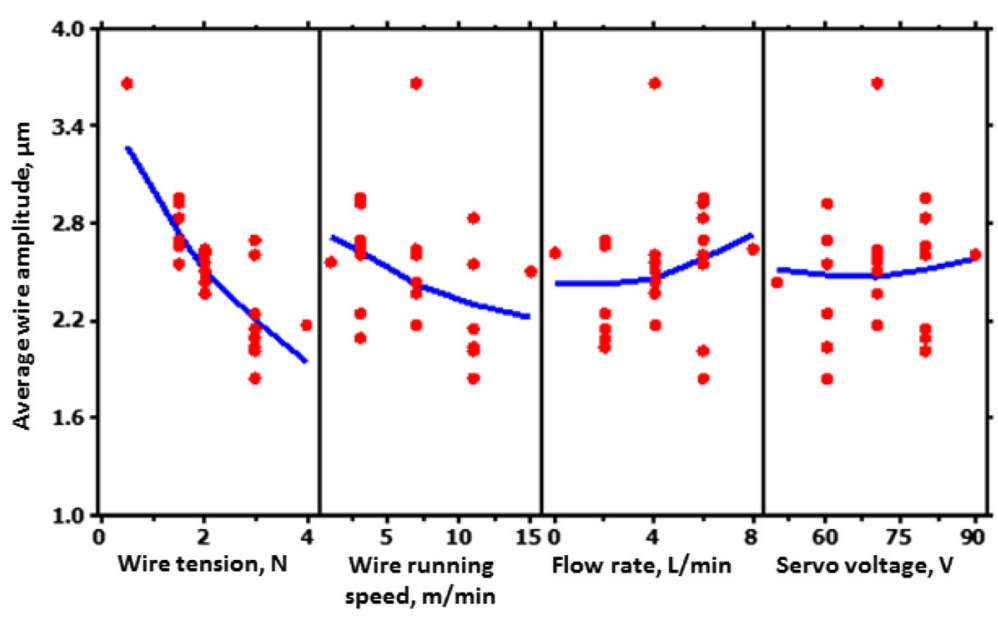

Fig. 3 Relationship between average wire amplitude and wire tension, wire running speed, flow rate and servo voltage 

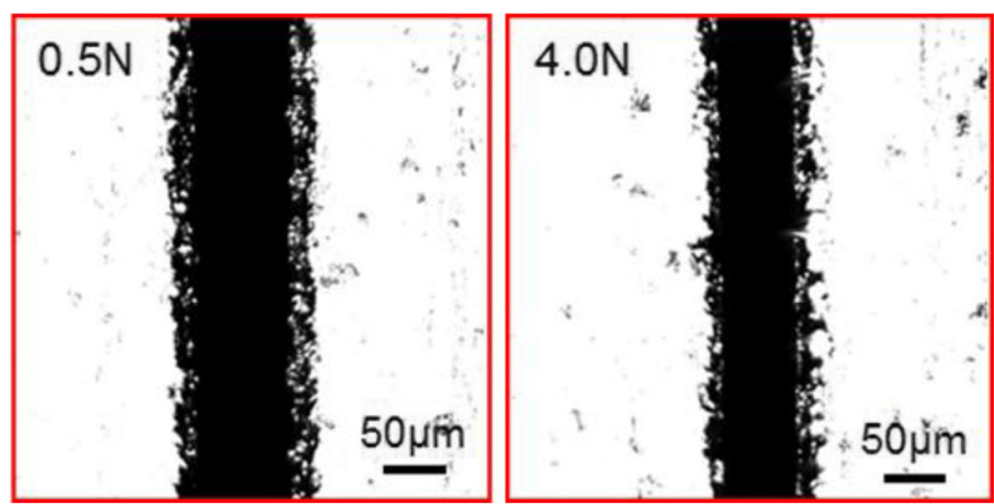

Fig. 4 Wire shape difference under wire tension 0.5 and $4.0 \mathrm{~N}$

When the wire running speed has a lower value, the amplitude slightly increases. The debris exclusion from the discharge gap is a little difficult at lower wire running speed because there is no high-speed flow of working fluid around the wire. Then, the debris stagnation occurs around the wire, which causes unstable machining and larger amplitude of wire vibration. When the wire running speed is higher, the debris is smoothly excluded.

Dielectric flow rate is the rate at which the dielectric fluid is circulated. Flow rate of the working fluid from jet nozzles is important for efficient machining. One of the forces exerted on the wire is the dielectric flow such that as the flow rate increases around the wire, the movement of the wire speeds up and thus the average wire amplitude increases.

Servo voltage acts as the reference voltage to control the wire advances and retracts. Figure 3 shows that there is little decrease of average wire amplitude with change of servo voltage from 50 to $70 \mathrm{~V}$. After that, the average wire amplitude increases slightly.

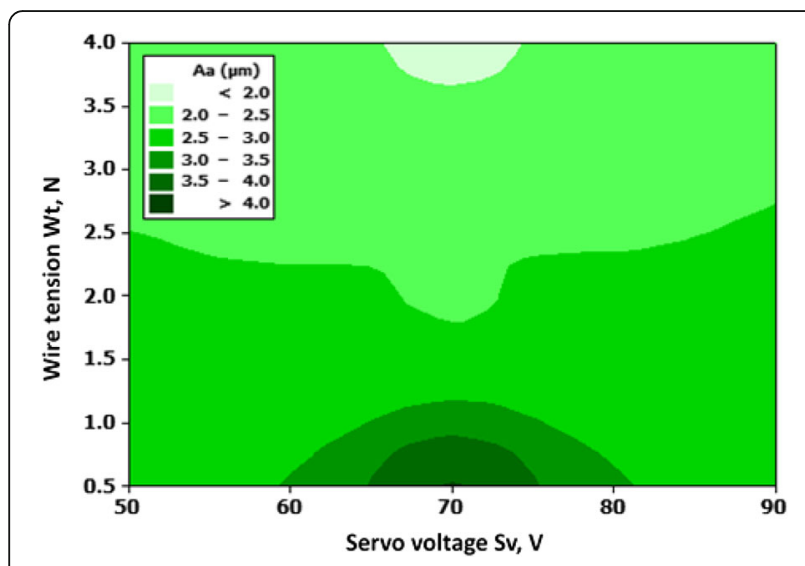

Fig. 5 Effect of wire tension and servo voltage in average wire amplitude
The effect of both wire tension and servo voltage on average wire amplitude is shown in the contour graph of Fig. 5. It can be concluded that the average wire amplitude has maximum value higher than $4.0 \mu \mathrm{m}$ of dark green color when wire tension values ranges between $1.0 \mathrm{~N}$ and $0.5 \mathrm{~N}$ with servo voltage values ranges between $65 \mathrm{~V}$ and $75 \mathrm{~V}$. However, the average wire amplitude has minimum value less than $2.0 \mu \mathrm{m}$ of light green when wire tension higher than $3.5 \mathrm{~N}$ and servo voltage between $65 \mathrm{~V}$ and $75 \mathrm{~V}$. Thus, it can be concluded that to minimize average wire amplitude, it is better to make the value of wire tension ranges between $3.5 \mathrm{~N}$ and $4.0 \mathrm{~N}$ in addition with servo voltage ranges between $65 \mathrm{~V}$ and $75 \mathrm{~V}$.

Figure 6 shows the effect of wire running speed and dielectric flow rate on average wire amplitude. It is found that the average wire amplitude has maximum values ranges between $2.5 \mu \mathrm{m}$ and $3.0 \mu \mathrm{m}$ of green color at the lower part of the figure when wire running speed values ranges between $3.0 \mathrm{~m} / \mathrm{min}$ and $10.0 \mathrm{~m} / \mathrm{min}$. However, the average wire amplitude has minimum values ranges between $2.0 \mu \mathrm{m}$ and $2.5 \mu \mathrm{m}$ of light green at the

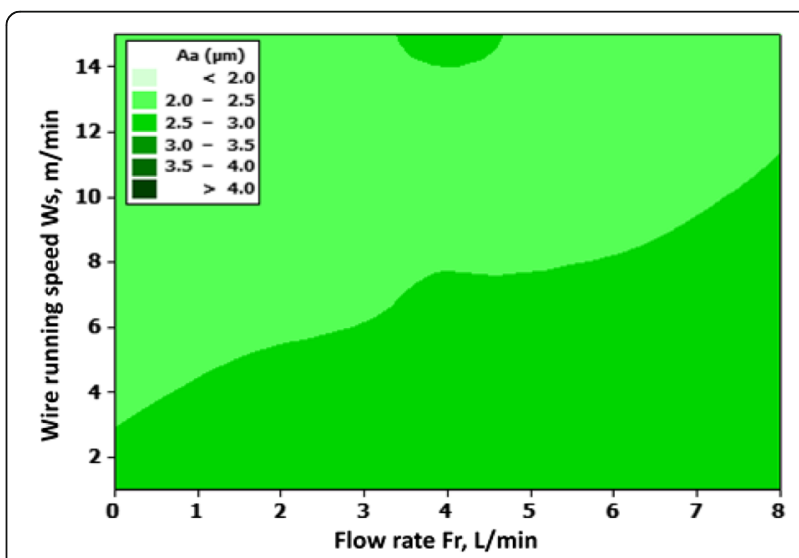

Fig. 6 Effect of wire running speed and flow rate in average wire amplitude 


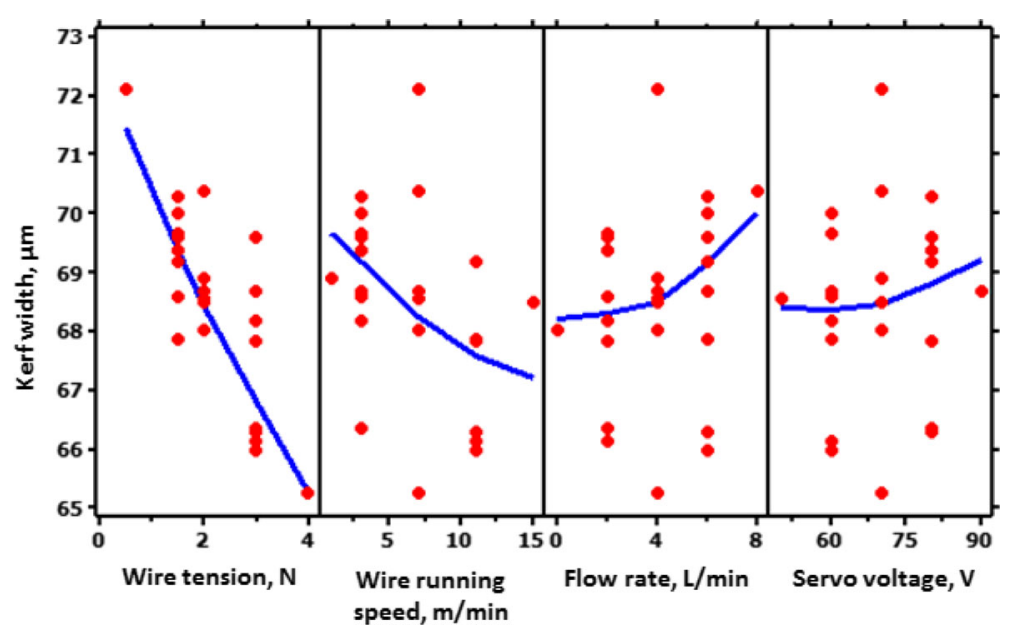

Fig. 7 Relationship between kerf width and wire tension, wire running speed, flow rate and servo voltage

higher part of the figure when wire running speed values ranges between $4.0 \mathrm{~m} / \mathrm{min}$ and $15.0 \mathrm{~m} / \mathrm{min}$ for the same range of dielectric flow rate $(0$ to $8.0 \mathrm{~L} / \mathrm{min})$. Thus, it can be concluded that to minimize average wire amplitude, it is better to make the value of wire running speed ranges between $4.0 \mathrm{~m} / \mathrm{min}$ and $15.0 \mathrm{~m} / \mathrm{min}$ for the same range of dielectric flow rate (0 to $8.0 \mathrm{~L} / \mathrm{min}$ ).

\section{Parametric influence on kerf width}

Figure 7 shows the relationship between kerf width and the effecting parameters such as wire tension, wire running speed, flow rate and servo voltage. Kerf width decreases directly with the increase of wire tension and wire running speed. However, it increases with the increase of flow rate and servo voltage. When the wire tension increases, the straightness of the wire increases and thus decreases the average wire amplitude and so decreases the resulted kerf width. It can be noticed that the kerf width decreases with the wire tension, which agrees with the variation of wire vibration amplitude with the wire tension

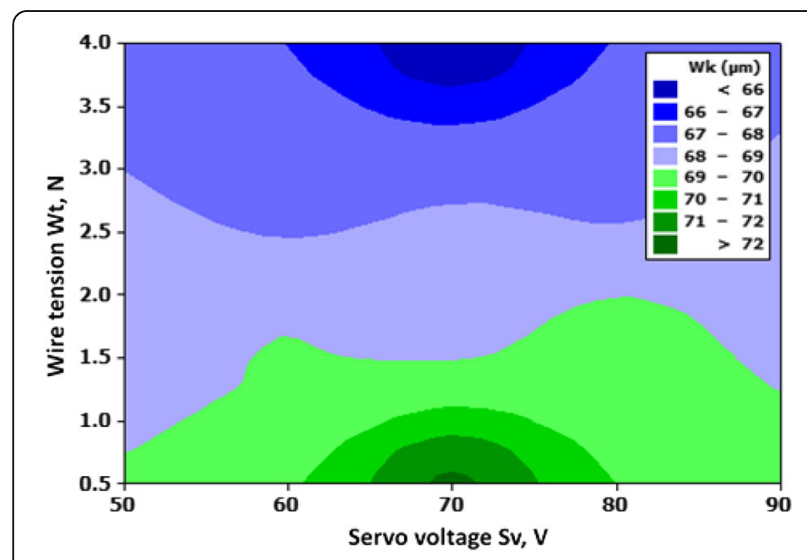

Fig. 8 Effect of wire tension and servo voltage in kerf width shown above. Therefore, the increase of wire amplitude results in the increase of kerf width. In other words, the wire amplitude and the machined kerf width can be decreased by increasing wire tension also in fine wire EDM.

Figure 8 shows the effect of wire tension and servo voltage on kerf width. It can be shown that the maximum kerf width of value higher than $72 \mu \mathrm{m}$ is located at the region of color dark green when the wire tension has value ranges between $0.7 \mathrm{~N}$ and $0.5 \mathrm{~N}$ with servo voltage values ranges between $69 \mathrm{~V}$ and $71 \mathrm{~V}$. However, the minimum kerf width of value less than $66 \mu \mathrm{m}$ is located at the region of color dark blue when the wire tension has values ranges between $3.5 \mathrm{~N}$ and $4.0 \mathrm{~N}$ with servo voltage values ranges between $65 \mathrm{~V}$ and $75 \mathrm{~V}$. Thus, it can be concluded that when wire tension values ranges between $3.5 \mathrm{~N}$ and $4.0 \mathrm{~N}$ in addition with servo voltage ranges between $65 \mathrm{~V}$ and $75 \mathrm{~V}$, minimum kerf width values resulted.

The contour graph relating between kerf width with both of wire running speed and dielectric flow rate can be shown in Fig. 9. The maximum kerf width of values

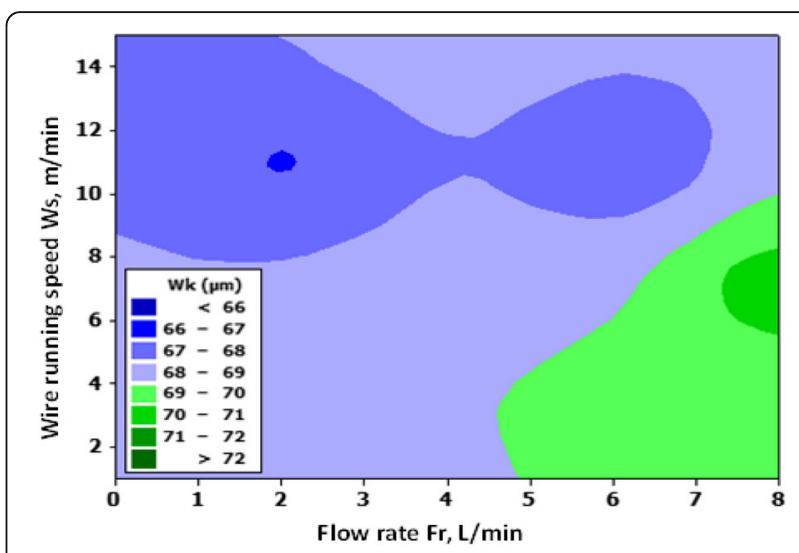

Fig. 9 Effect of wire running speed and flow rate in kerf width 
Table 8 Optimal values of WEDM parameters

\begin{tabular}{lll}
\hline Process parameters & \multicolumn{2}{l}{ Value obtained } \\
\cline { 2 - 3 } & Average wire amplitude & Kerf width \\
\hline Wire tension, $N$ & $3.5-4.0$ & $3.5-4.0$ \\
Wire running speed, $\mathrm{m} / \mathrm{min}$ & $4.0-15.0$ & $10.5-11.5$ \\
Flow rate, L/min & 0 to 8.0 & $1.5-2.5$ \\
Servo voltage, $\mathrm{V}$ & $65-75$ & $65-75$ \\
\hline
\end{tabular}

ranges between $70 \mu \mathrm{m}$ and $71 \mu \mathrm{m}$ that located at the region of color moderate green when the wire running speed has value ranges between $5.0 \mathrm{~m} / \mathrm{min}$ and $8.0 \mathrm{~m} /$ min with dielectric flow rate values ranges between $7.0 \mathrm{~L} / \mathrm{min}$ and $8.0 \mathrm{~L} / \mathrm{min}$. whereas, the minimum kerf width of value less than $66 \mu \mathrm{m}$ is located at the region of color dark blue when the wire running speed has values ranges between $10.5 \mathrm{~m} / \mathrm{min}$ and $11.5 \mathrm{~m} / \mathrm{min}$ with dielectric flow rate values ranges between $1.5 \mathrm{~L} / \mathrm{min}$ and $2.5 \mathrm{~L} / \mathrm{min}$. Thus it can be concluded that to minimize kerf width, it is better to make the value of wire running speed ranges between $10.5 \mathrm{~m} / \mathrm{min}$ and $11.5 \mathrm{~m} / \mathrm{min}$ in addition with dielectric flow rate ranges between $1.5 \mathrm{~L} /$ min and $2.5 \mathrm{~L} / \mathrm{min}$.

\section{Optimality search}

For the purpose of achieving stable wire electrical discharge machining, optimal combination of the various effecting process-variables such as the wire tension, wire running speed, flow rate and servo voltage, can be analyzed based on the developed mathematical models. The optimal search was formulated for the various process variable conditions based on minimizing average wire amplitude and kerf width values. The optimal combination of various process variables thus obtained within the bounds of the developed mathematical models and contour graphs. The optimal values resulted have been listed, as shown in Table 8 .

\section{Conclusions}

The analysis of the experimental observations highlights that the wire tension, wire running speed, flow rate and servo voltage in WEDM greatly affect average wire vibration and kerf width. Main conclusions obtained are as follows;

1. Average wire amplitude decreases with the increase of wire tension and wire running speed. However, average wire amplitude increases with dielectric flow rate. Servo voltage has a weak influence on average wire amplitude.

2. Kerf width decreases directly with the increase of wire tension and wire running speed. However, kerf width increases with the increase of flow rate and servo voltage.

3. To minimize average wire amplitude, the value of wire tension is recommended to range between $3.5-4.0 \mathrm{~N}$ in addition with a servo voltage ranging between $65-75 \mathrm{~V}$.

4. When the value of wire running speed ranges between 4.0 and $15.0 \mathrm{~m} / \mathrm{min}$ for the range of dielectric flow rate from $0-8.0 \mathrm{~L} / \mathrm{min}$, minimum average wire amplitude has been achieved.

5. Minimum kerf width values resulted under wire tensions ranging between $3.5-4.0 \mathrm{~N}$ while the servo voltages ranged between $65-75 \mathrm{~V}$.

6. For minimal kerf widths, the WEDM process is preferred to operate under wire running speeds between $10.5-11.5 \mathrm{~m} / \mathrm{min}$ in addition to dielectric flow rates ranging between $1.5-2.5 \mathrm{~L} / \mathrm{min}$.

\section{Abbreviations}

CCD: Central composite designs; $F_{r}$ : Flow rate; $S_{v}$ : Servo voltage; $W_{s}$ : Wire running speed; $W_{t}$ : Wire tension

\section{Funding}

This research got no financial help from any funding organization for the authorship or publication of this article.

Authors' contributions

There only one author for this manuscript, Prof. SSH.

\section{Competing interests}

The author declares that he/she has no competing interests.

Received: 11 November 2016 Accepted: 12 January 2017

Published online: 28 January 2017

\section{References}

Beltrami I, Bertholds A, Dauw D (1996) A simplified post process for wire cut EDM. J Mater Process Technol 58(4):385-389

DIPP-Motion Pro User's Manual. www.ditect-corp.com/products/dipp_motionv.html

Habib S (2009) Study of the parameters in electrical discharge machining through response surface methodology approach. Appl Math Model 33: 4397-4407

Habib S, Okada A (2016a) Study on the movement of wire electrode during fine wire electrical discharge machining process. J Mater Process Technol Elsevier 227:147-152

Habib S, Okada A (2016b) Experimental investigation on wire vibration during fine wire electrical discharge machining process. Int J Adv Manuf Technol Springer 84(9):2265-2276

Herrero A, Azcarate S, Rees A, Gehringer A, Schoth A, Sanchez JA (2008) Influence of force components on thin wire EDM, 4th International Conference on Multi-Material Micro Manufacture, 4 M2008, Cardiff, UK.

Kumar A, Singh DK (2012) Performance Analysis of Wire Electric Discharge Machining (W-EDM). Int J Eng Res Technol (IJERT) 1(4):1-9

Kumar AH, Kumar V, Kumar J (2013) Parametric Effect on Wire Breakage Frequency and Surface Topography in WEDM of Pure Titanium. J Mech Eng Technol 1(2):51-56

Mahfouz SY (1999) Design Optimization of Structural Steelwork. University of Bradford, Ph. D. thesis, UK, pp 15-29

Montgomery DC (1997) Design and analysis of experiments. John Wiley \& Sons, New York

Nain SS, Garg D, Kumar S (2015) A Study on Performance Characteristics in WEDM. Int J Sci Prog Res (IJSPR) 8:34-42

Puri AB, Bhattacharyya B (2003) An analysis and optimization of the geometrical inaccuracy due to wire lag phenomenon in WEDM. Int J Mach Tools Manuf 43(2):151-159 
Shichun D, Xuyang C, Dongbo W, Zhenlong W, Guanxin C, Yuan L (2009) Analysis of kerf width in micro-WEDM. Int J Mach Tools Manuf 49(10):788-792

Tomura S, Kunieda M (2009) Analysis of electromagnetic force in wire-EDM. Precis Eng 33(3):255-262

Wentai S, Zhidong L, Mingbong Q, Zongjun T (2015) Wire tension in high-speed wire electrical discharge machining. Int J Adv Manuf Technol

\section{Submit your manuscript to a SpringerOpen ${ }^{\circ}$} journal and benefit from:

- Convenient online submission

- Rigorous peer review

- Immediate publication on acceptance

- Open access: articles freely available online

- High visibility within the field

- Retaining the copyright to your article

Submit your next manuscript at $>$ springeropen.com 